\title{
La noción de guerra revolucionaria en Fernando Landazábal Reyes y sus repercusiones en el conflicto armado colombiano
}

\author{
The Notion of Revolutionary War in Fernando \\ Landazábal Reyes and its Repercussions in Colombian \\ Armed Conflict
}

Edgar Velásquez Rivera'

\section{Resumen}

Una de las características del conflicto armado colombiano es el asesinato de civiles por parte de miembros de organismos de seguridad del Estado. Estos justifican sus acciones acusándolos de participar en una estrategia subversiva liderada por el Partido Comunista Colombiano. Esta, a su vez, se origina supuestamente en la guerra revolucionaria, antítesis de la guerra clásica. En Colombia, quien con mayor profundidad abordó el fenómeno de la guerra revolucionaria fue el oficial Fernando Landazábal Reyes. Este artículo pretende mostrar los principales rasgos de la guerra revolucionaria, desde la perspectiva del mencionado militar y la manera como pudo haber repercutido en el conflicto armado colombiano.

\section{Palabras clave}

Guerra, revolución, infiltración, violencia, subversión, anarquía, poder.

Abstract

One of the characteristics of the armed Colombian conflict is the murder of civilians by the members of organisms of national security, who accuse those they kill of participating in a subversive strategy led by the Colombian Communist Party, which in turn supposedly originates in the revolutionary war, antithesis of the classic war. In Colombia, the phenomenon of revolutionary war has been approached in depth by the officer Fernando Landazábal Reyes. This article tries to show the principal features of the revolutionary war, from the perspective of the mentioned military man and the way since it could have reverberated in the armed colombian conflict.

Key words:

War, revolution, infiltration, violence, subversion, anarchy, power.

Artículo recibido el 15 Febrero de 2012 y aprobado el 30 Marzo de 2012

1 Doctor en Historia de la Pontificia Universidad Católica de Chile. Posdoctorado, Universidad Nacional de Córdoba (Argentina) Profesor de la Universidad del Cauca. velasquezrivera@gmail.com 


\section{El hombre}

Fueron sus padres los educadores Luis Landazábal Tarazona (profesor y regente del Colegio Provincial de los Hermanos Cristianos en Pamplona y secretario de educación en Norte de Santander) y Dolores Reyes Gutiérrez, quienes tuvieron trece hijos, de los cuales el menor fue Fernando, quien nació en Pamplona (Norte de Santander, Colombia), el jueves 13 de julio de 1922. Fernando Landazábal Reyes hizo sus estudios primarios en el Liceo San Francisco, en su ciudad natal. Inició su formación secundaria en la institución donde laboró su padre y allí cursó hasta quinto año de bachillerato (grado décimo en la actual organización de la escolaridad en Colombia): "Mi padre murió cuando yo tenía seis meses" (Medina, 2000, 55).

Ingresó a la Escuela Militar de Cadetes en Bogotá, de donde se graduó como oficial del Ejército de Colombia el 6 de diciembre de 1947, en el arma de Artillería (Yarce, 1981,13). En marzo de 1948 presenció los horrores de la violencia protagonizada por liberales y conservadores y participó desde el 9 de abril de 1948 y durante un lapso de cinco días en la defensa de la Casa de Nariño (símbolo de la institucionalidad del país) ante el ataque de quienes protestaban por el asesinato del líder liberal Jorge Eliécer Gaitán. En 1950 adelantó el curso de Armas Básicas y Pesadas de Infantería, en Fort Gulick, en la Escuela de las Américas. $\mathrm{Al}$ año siguiente tomó el curso de Administración Militar dictado por el Comando del Ejército Colombiano y fue designado instructor de la Escuela Militar de Cadetes.

En 1952 fue transferido al Batallón de Infantería Número 1 Colombia, para viajar a Corea como parte de las fuerzas de las Naciones Unidas. Participó en la guerra con ese país desde el 1 de enero de 1952 hasta el 16 de abril de 1953. Allí conoció de primera mano la bipolaridad Este-Oeste. Retornó a la Escuela Militar de Cadetes en calidad de instructor. En 1954 viajó a Fort Sill (Oklahoma) y adelantó el curso básico de Artillería de Campaña, el cual finalizó el 1 de febrero de 1955. Entre 1957 y 1958 viajó nuevamente a los Estados Unidos para hacer el curso avanzado de Artillería y Proyectiles Guiados, del cual se graduó el 6 de junio de 1958 en la Artillery and Missile and Air Defense School.
El 8 de septiembre de 1958 fue nombrado jefe de instrucción de la Brigada de Institutos Militares. En julio de 1959 adelantó el curso de capitanes para ascenso a Mayor. Desde noviembre de 1959 hasta finales de 1962 fue el Segundo Comandante del batallón de artillería número 6, Tenerife, en Neiva, departamento del Huila. El 21 de julio de 1962 se le otorgó la condecoración Orden de Boyacá en el grado de Oficial, según decreto número 1952. Mediante Decreto número 3345 del 17 de diciembre de 1962, fue llamado para adelantar el curso de Oficial de Estado Mayor. De igual modo, fue jefe de relaciones públicas del Comando del Ejército. Ascendido a Teniente Coronel, fue nombrado jefe del departamento 5 de asuntos civiles del Comando del Ejército, jefe del departamento de inteligencia del Estado Mayor del Ejército. En 1964, por Decreto número 2729 del 4 de noviembre de ese año, fue nombrado comandante del Batallón de Artillería Número 3 "Palacé", en Buga, departamento del Valle del Cauca.

El 1 de enero de 1966 fue nombrado profesor de planta de la Escuela Superior de Guerra, como jefe del departamento de estrategia. El 1 de septiembre de 1966, a través del Decreto número 2226 fue trasladado al Comando General de las Fuerzas Militares y destinado al cargo de inteligencia en el mismo comando. Mediante Resolución número 02744 del 10 de mayo fue comisionado a la Escuela de las Américas para que dictara conferencias sobre operaciones sicológicas y acción cívico-militar en operaciones contraguerrilla. Mediante Resolución número 02744 del 27 de abril de 1966 fue nombrado profesor de filosofía militar, en la Escuela Militar de Cadetes.

Por medio de la resolución número 00824 del 14 de febrero de 1967, fue nombrado profesor militar externo, sin perjuicio del cargo que desempeñaba en la Escuela Superior de Guerra en el área de táctica. Fue representante del Ministerio de Defensa en la junta directiva del Instituto Geográfico Agustín Codazzi, según la Resolución número 03302 del 19 de junio de 1967. En 1968, por Decreto número 811 del 25 de mayo, fue ascendido al grado de Coronel y ocupó el cargo de jefe de Estado Mayor de la Cuarta Brigada, en Medellín, departamento de Antioquia. 
En 1969, ocupó el cargo de jefe de personal del Ejército Nacional y de agregado militar, naval y aéreo en la embajada de Colombia ante el gobierno de Brasil, según decreto 007. Concluida esta misión, fue convocado para adelantar el curso de Altos Estudios Militares en la Escuela Superior de Guerra y en 1972 adelantó el curso de Administración Pública en la ESAP. Ascendido a Brigadier General, fue nombrado Comandante de la Tercera Brigada, en Cali, Departamento del Valle del Cauca, cargo que ocupó entre 1973 y 1974. Según el Decreto número 383, del 6 de marzo de 1975, se le nombró secretario ejecutivo permanente del Consejo Superior de Defensa Nacional y por medio del Decreto 768 del 30 de marzo de ese mismo año, fue nombrado comandante de la Brigada de Institutos Militares (BIM), en Bogotá, periodo durante el cual organizó los cursos de la reserva para profesionales.

Ascendido al grado de Mayor General, fue nombrado jefe de la delegación colombiana ante la Junta Interamericana de Defensa y ministro consejero en la embajada colombiana en la Organización de Estados Americanos (OEA), y se desempeñó como agregado militar, naval y aéreo ante la Junta Interamericana de Defensa en Washington en 1977. De regreso a Colombia, fue nombrado jefe de Estado Mayor Conjunto y Secretario Ejecutivo del Consejo Superior de la Defensa Nacional. Mediante el Decreto número 2913 del 28 de noviembre de 1979, fue ascendido al grado de General. El 1 de septiembre de 1980 fue nombrado comandante del Ejército (Semana, 1982a, 28).

El presidente Belisario Betancur Cuartas, tras su posesión el 7 de agosto de 1982 y con un gabinete mayoritariamente conservador, designó como ministro de Defensa Nacional a Landazábal Reyes (Semana, 1982b, 30). Su retiro de este gobierno (y por tanto el fin de su carrera militar) ocurrió por la reunión que el Jefe de Estado sostuvo en Madrid (España) con miembros del M-19. El militar lo tomó como un desaire hacia las Fuerzas Militares. Consideró que el gobierno nacional hacía innecesarias y excesivas concesiones a las guerrillas. Una vez fuera de la institución castrense, se dedicó a la política y fundó el Movimiento Integracionista Nacional, con el cual participó como candidato a la Asamblea Nacional Constituyente en 1991, sin alcanzar éxito notable alguno (Durán, 2008, 15)1.

Fue invitado por los Estados Unidos a la Escuela de las Américas para que dictara conferencias sobre acción psicológica y guerra de guerrillas. Perteneció al arma de artillería y, en su honor, el Batallón de Artillería No 13 fue bautzado con su nombre. Fue condecorado por los gobiernos de Colombia, los Estados Unidos, Francia, Corea del Sur, Venezuela, Ecuador y Brasil (Fuerzas Militares, 1998, 245)2. A lo largo de su ejercicio profesional, en las distintas Escuelas de las Armas y Servicios, fue profesor de materias como Topografía, Historia, Acción Psicológica, Matemáticas, Táctica, Operaciones Contra Guerrillas, Filosofía y Balística. Su producción intelectual expresada en una veintena de libros y otro tanto de artículos, son materiales de consulta en la Escuela Superior de Guerra y en las escuelas de las diversas armas. Así mismo, se le reconoce como autor de poemas en distintos estilos literarios.

El 12 de diciembre de 1992, el Partido Conservador Colombiano lo nombró como uno de los nueve miembros de su dirección nacional (Fuerzas Militares, 1998, 245). En 1996, Landazábal Reyes pidió mediante un comunicado, junto a un grupo de dirigentes políticos y empresariales que se autodenominó "Por la reconstrucción nacional", el retiro del presidente Ernesto Samper Pizano de su cargo El Tiempo, 1996, 9A). Landazábal Reyes fue asesinado el martes 12 de mayo de 1998, en Bogotá (a las 7:50 a.m.), después de haber estado en el Ejército Nacional de Colombia durante 36 años y alcanzado los máximos grados y honores 3 . A través de sus obras y declaraciones generó múltiples controversias, no

1 Durán, Diana Carolina. El hombre del número 13. En: El Espectador, Bogotá, Mayo 11 de 2008, 15.

2 Fuerzas Militares. Escritos inéditos del Señor General Fernando Landazábal Reyes. Bogotá, 1998, 245.

3 En la coyuntura de su asesinato, se conocieron amenazas contra la vida de los candidatos presidenciales Andrés Pastrana Arango y Horacio Serpa Uribe, de los partidos conservador y liberal, respectivamente. De igual modo se registró el asesinato de los defensores de derechos humanos Jesús María Valle en febrero de 1998 y de María Arango y Eduardo Umaña en abril del mismo año, así como la muerte violenta de 65 personas durante la semana precedente al asesinato del oficial. 
exentas de notable subjetividad. Existe una subjetividad social y una subjetividad individual.

\section{La subjetividad}

La subjetividad social es el conjunto de representaciones que significan y producen sentidos, los cuales expresan el tejido social en que se producen. En la configuración de la subjetividad social aparecen estrechamente relacionados fenómenos sociales como los mitos, el humor, las formas habituales de pensamiento, los códigos morales de las dependencias e instituciones sociales, la organización del sentido común, los códigos emocionales de relación, la organización social de los repertorios de respuestas, el lenguaje, las representaciones sociales, los discursos, los comportamientos institucionalizados (González Rey, 2002, 121).

La subjetividad individual, por su parte, está constituida por elementos de la subjetividad social que aparecen en ella, no a modo de copia, sino como expresión diferenciada que se articula con los sentidos subjetivos únicos que se desarrollan en la historia individual irrepetible de cada sujeto (González Rey, 2002, 121). La subjetividad individual se produce en espacios sociales constituidos históricamente; por tanto, en la génesis de toda subjetividad individual están los espacios constituidos a partir de una determinada subjetividad social, que anteceden la organización del sujeto psicológico concreto, y quien aparece en su ontogenia como un momento de un escenario social constituido en el curso de su propia historia. El desarrollo del sujeto individual da lugar a procesos de subjetivación social nuevos, a nuevas redes de relaciones sociales que actúan como momentos de cambio de las formas anteriores de funcionamiento del sistema. Los procesos de subjetivación individual están siempre articulados a sistemas de relaciones sociales; por tanto, tienen un momento de expresión en el plano individual y otro en el social, aunque uno y otro generan consecuencias diferentes que se integran en dos sistemas que surgen en la propia tensión recíproca en que coexisten: la subjetividad social y la individual.

Incidieron en la configuración de la subjetividad individual de Landazábal Reyes, un abigarrado conjunto de fenómenos de las más diversas tradiciones, entre los que se destacan la Iglesia Católica $y$, con ella, el integrismo, el hispanismo, el carlismo y autores como Juan Donoso Cortés, para quien "El catolicismo es un sistema de civilización completo, es un sistema de ideas conservadoras; tan completo, que en su inmensidad lo abarca todo: la ciencia de Dios, la ciencia del ángel, la ciencia del universo, la ciencia del hombre" (Donoso, 2006, 13). Desde tal perspectiva, el orden pasó del mundo religioso al mundo moral, y del mundo moral al mundo político. Según dicho autor, "Dos cosas son de todo punto imposibles en una sociedad verdaderamente católica: el despotismo y las revoluciones" (Donoso, 2006, 17).

Landazábal Reyes tomó como propios los postulados de la doctrina social consagrados en encíclicas y los expuso como solución a las diferencias entre burgueses y proletarios. De la encíclica Rerum Novarum (15 de mayo de 1891), considerada la "Carta Magna del Orden Social” (Acción Católica Española, 1955, 359), así como de la encíclica Cuadragésimo Anno (15 de mayo de 1931), sobre la restauración del orden social en plena conformidad con la ley evangélica, hace énfasis en la defensa de la propiedad privada, el capital, el trabajo y la concordia entre las clases; en la encíclica Divini Redemptoris (19 de marzo de 1937), que aborda el comunismo ateo, se encuentran trazas en el pensamiento de Landazábal Reyes, especialmente en lo referente a la defensa de la cultura occidental y sus valores.

De igual modo incidieron en la cimentación de la subjetividad de Landazábal Reyes la educación primaria recibida en Pamplona, los cánones axiológicos impartidos en su entorno familiar anclados en el conservatismo y el catolicismo y luego su formación en la Escuela Militar, donde conoció las principales teorías sobre el desarrollo vigentes para la época y se acercó a la perspectiva cepalina. Por esa vía y por su permanente formación dentro y fuera de Colombia, leyó las obras clásicas de Emmanuel Kant, G. W. Friedrich Hegel, Napoleón Bonaparte, Carlos Marx, Federico Engels, Vladimir Ilich Lenin, Henry Kissinger, Francisco Franco, Charles DeGaulle y Mao Tse-Tung, quien argumentó la existencia 
de dos tipos de guerras: justas (revolucionarias) e injustas (contrarrevolucionarias). También leyó a Ho Chi Minh, Fidel Castro, Ernesto Guevara y el general francés André Beaufre, aparte de literatura universal, latinoamericana y colombiana. Estudió el fascismo, el nazismo, la revolución francesa, así como las revoluciones soviética, china y cubana. Conoció las experiencias subversivas y antisubversivas de Indochina, Argelia, Cuba, Perú, Venezuela y Filipinas.

La experiencia de vida y su práctica, le permitieron apuntalar y controvertir teorías; en algunos análisis recurrió al método comparativo. Agudo observador del diario acontecer del mundo y de Colombia. Como se puede observar, no tuvo un solo torrente de influencias, cuestión que se refleja en su compleja subjetividad, desde la que construyó su enemigo: el socialismo, el comunismo, la subversión y las organizaciones guerrilleras de orientación marxista actuantes a través de la guerra revolucionaria. Su noción de guerra revolucionaria, en tanto resultante de la subjetividad social y de la subjetividad individual, y entendida como una construcción histórica referida a un asunto ideológico como lo fue el de la subversión, arrojó como resultado una perspectiva ideológica de derecha, desde la cual comprendió los distintos fenómenos militares, sociales, económicos, culturales y políticos de los que se ocupó.

Los anteriores hechos, unidos a la formación castrense recibida dentro y fuera de Colombia, y a su incursión en campos de la ciencia, la técnica y la literatura hicieron de Landazábal Reyes un militar que desde su oficio castrense y fuera de él, a través de sus obras y de entrevistas y conferencias, desarrolló y abordó el fenómeno guerrillero en Colombia. Figura entre los oficiales colombianos que más polémica desató en virtud de sus posiciones, respecto a los problemas que enfrentó en el ejercicio de sus funciones.

Las guerrillas colombianas, especialmente las que se originaron en la segunda mitad del siglo $\mathrm{XX}$, encontraron en Landazábal Reyes al más férreo oponente, tanto en el escenario de la confrontación armada, como en el de la controversia ideológica.
No en vano se le reconoce en Colombia como el emblema o arquetipo de la lucha antiguerrillera, rasgo que le implicó roces con los poderes ejecutivo, legislativo y judicial, así como con partidos políticos de izquierda y organizaciones defensoras de derechos humanos, entre otros. Sin embargo, guardó distancia de quienes vieron al estamento castrense como una alternativa de poder ante las crisis de la coyuntura en que actuó, al señalar de manera categórica en agosto de 1981 que intentar presentar a las Fuerzas Armadas y a sus jefes como una alternativa de poder demostraba un desconocimiento absoluto de la institución y de sus hombres. En 1982 propuso aplicar a las guerrillas las dos tácticas que, según el mismo, ellas mismas aplican: la vía pacífica y la vía armada.

Consideró imposible terminar con la subversión “...mientras no se modifiquen, en el dominio social, político y económico, las condiciones objetivas y subjetivas que, cada día, rompen y deterioran el consenso" (Landazábal Reyes, 1969, 25)4 y que servían de base a los planteamientos de las guerrillas, pero proponía que de manera simultánea estuviese la acción militar propiamente dicha. Landazábal Reyes, fruto de la subjetividad propia de la Guerra Fría, dedicó especial atención al fenómeno de la guerra revolucionaria.

\section{La noción de guerra revolucionaria en Fernando Landazábal Reyes}

Según este oficial, hasta la Segunda Guerra Mundial la estrategia buscó la destrucción de las fuerzas armadas del adversario, por considerar en sus formaciones la representación medular del estamento social por ellas defendido y porque veía en ellas la última razón para esgrimir el último argumento de la política, para obtener la decisión favorable a la propia voluntad. Fue esta la estrategia que determinó el criterio bélico de Occidente hasta el mencionado conflicto mundial (Landazábal Reyes, 1975, 42).

Surgió allí la estrategia revolucionaria, que apoyada más tarde en la política soviética de la coexis-

4 Landazábal Reyes, Fernando (Coronel). Estrategia de la subversión y su desarrollo en América Latina. Bogotá, Pax, 1969, 25. 
tencia pacífica y en la norteamericana que engendró la Alianza para el Progreso, llevó a las naciones a buscar victorias distintas a las típicamente castrenses que se venían buscando desde los primeros tiempos. Para este fin solo fue necesario forzar a las formaciones militares a que participaran en una contienda en la que el énfasis no estaba en el propio campo de batalla, sino más allá de las escaramuzas, detrás de los combates, casi por completo en el campo de la política, ya que cada acción bélica no era otra cosa que la confrontación violenta de un poder político con otro, como nunca dejó de serlo. Desde su percepción, señaló:

...las grandes potencias midieron sus fuerzas y la capacidad decisoria del adversario, en el empleo de las nuevas armas, para lo cual seleccionaron pequeños países, en los que a la sombra de un conflicto, aparentemente interno, creado desde afuera, pudieron medirse los potenciales de unos y otros, lo mismo que sus capacidades para expandir o detener la nueva forma de poder, sin comprometer a fondo la fuerza de las armas en el propio terreno de los poderes en pugna. Surgió entonces la guerra limitada como una necesidad para evitar la guerra total y se presentó como una mezcla de lo antiguo y de lo nuevo, una contienda con la máscara del conflicto civil pero con la tutela de los antagonismo de los grandes poderes mundiales, al amparo de la controversia de ficticios conflictos internos, caldeados por los ideales que se disputaban su dominio o expansión. Se concretó para unos y otros el más claro concepto de lo que debía considerarse como guerra justa, siendo para Occidente la "agresión” la justificación de la intervención armada y para Oriente la "liberación” de los pueblos subyugados. (Landazábal Reyes, 1975, 43)

Algunos estudios estadounidenses de 1962, plantearon que la guerra interna (guerras de liberación o guerras justas) y la guerra de guerrillas eran nuevas tácticas del comunismo liderado desde Moscú y, ese mismo año, fueron publicados en Colombia. Propusieron impedir el avance del comunismo desde tres escenarios: la seguridad militar, la modernización y las reformas y factores políticos (1962). Estos tres aspectos son recurrentes en los planteamientos de Landazábal Reyes. De lo anterior se deduce la influencia directa de los estrategas estadounidenses sobre él.

Sobre la guerra de guerrillas, es preciso señalar que está profundamente enraizada en el esbozo marxista de la doctrina militar. Según este concepto, en la lucha del proletariado contra sus explotadores capitalistas no intervendrían ejércitos regulares ni habría frentes definidos, sino que sería una guerra civil, adelantada por ambas clases sociales. La guerra de guerrillas, dice Raymond L. Garthoff, fue puesta a prueba en la revolución bolchevique y en la guerra civil posterior. La formación de un mando y control centralizados, con disciplina rígida por los revolucionarios profesionales, imprimió su sello a la lucha, orientándola hacia la creación de ejércitos regulares de la clase proletaria, iguales a los de la clase explotadora (Garthoff, 1956, 434).

Surgió, con el cambio de estrategia, la mejor posibilidad para que el marxismo aplicara su estrategia de la violencia. Haber escogido la justificación de la guerra, desde su propio concepto de liberación, hizo que su propia política internacional se tornara más agresiva, obligando a Occidente a sostener conflictos de tipo defensivo, en los que la iniciativa estuvo, en el aspecto global del conflicto, en manos de sus adversarios. Desde su punto de vista:

Los estados capitalistas se vieron, pues, ante la amenaza de las guerras de liberación gestadas por la agresión indirecta. Las fuerzas militares asumieron un nuevo papel en la conducción de la política defensiva, desplazándose al centro de gravedad de su dispositivo, de la periferia hacia el centro de los territorios de la nación afectada. Se hizo entonces presente la nueva estructura mental de los ejércitos, especialmente en los países seleccionados como presas de la disputa entre las grandes potencias. Pues fue entonces cuando estas instituciones se vieron abocadas a participar en la guerra esencialmente política. (Landazábal Reyes, 1975, 44)

Por consiguiente, se hizo necesario para los hombres de armas el estudio de las ideologías, la comprensión de los diversos sistemas políticos, sociales y 
económicos, el conocimiento de las diversas formas de estructuraciones estatales, los fines de las instituciones y, en la búsqueda de esa nueva información, los ejércitos tomaron la conciencia del verdadero valor de su fuerza para la protección de los pueblos. A lo largo de los años se fueron constituyendo en verdaderos factores para la garantía de la libertad o el sostenimiento de la tiranía, según el adoctrinamiento ideológico recibido, como consecuencia del sistema particular de la nación de la que formaron parte, según aclaró Landazábal Reyes $(1975,44)$.

Para él, la estrategia dejó entonces de mirarse a través de ejes, direcciones y acciones, para realizarse más allá de las fronteras. Convergió hacia el propio territorio de las pequeñas naciones por el surgir del fermento revolucionario alimentado paulatinamente por la subversión y la insurrección, que permitieron la presencia de formaciones enemigas en el propio campo y con los propios elementos de la estructura nacional, como fuerzas muchas veces intangibles de poderes extraterritoriales que forzaban en el nuevo ambiente la violencia fratricida, con el claro propósito de dominar pueblos sin tener que acudir al viejo y obsoleto procedimiento de las invasiones territoriales regulares.

Según su criterio, llegó entonces el adoctrinamiento ideológico a los ejércitos que ante la contienda de las grandes potencias y ante su búsqueda de predominio mundial, llevó a los ejércitos de los países en desarrollo ya no a defender o disputar esta o aquella posición, este o aquel sector del terreno, sino este o aquel sistema. Esto operaba mediante la acción amenazante hacia sus pueblos, la erradicación por la violencia de sus ideologías, su sentido del ser, la sociedad, el Estado, el capital y el trabajo, para llevarlos a practicar el sistema que el enemigo declarado les quería imponer como única solución para convivir en el entendimiento y fijar el desarrollo armónico de una sociedad común, con las mismas aspiraciones, limitaciones y derechos en los campos sociales, políticos y económicos especialmente.

Surgieron en esta ocasión los ejércitos ideológicos y con ellos se hizo presente la politización de los ejércitos en América Latina "y en muchas naciones se vieron forzados a asumir el poder contra los pro- pios mandatos de su constitución, en prevención del mantenimiento de un orden establecido y aceptado como digno de defenderse según los dictados, pactos, compromisos y doctrinas emanadas, custodiadas y promulgadas por la Junta Interamericana de Defensa" (Landazábal Reyes, 1975: 46). Surgieron los gobiernos militares, en muchos lugares con la anuencia de las corrientes políticas mayoritarias de la nación, frente a las perspectivas de un cambio radical en las estructuras del sistema impulsado por la subversión a través de la guerra revolucionaria (Landazábal Reyes, 1975, 46).

Landazábal Reyes consideró la guerra revolucionaria como la antítesis de combate opuesta a la guerra clásica. Alguien debía tomar la iniciativa de su aplicación. Ese alguien, dijo, fue el Partido Comunista "...que no pudiendo defender sus ideas en el amplio campo de la controversia filosófica, comprendió que era más lucrativo para su causa sembrar el terror entre los pueblos, para poder cerrar las cadenas de la esclavitud con el eslabón de hierro del pavor colectivo y la llave de acero de la impotencia social para la protesta o la rebeldía" (Landazábal Reyes, 1966, 11).

La guerra revolucionaria no era, pues, más que un aspecto de la política comunista; era una condición que exigía el partido para garantizar su supervivencia y una práctica esencial en la que debían participar necesariamente todos sus afiliados. Por ello todo comunista era un miliciano, todo comunista era un individuo dispuesto a realizar cualquiera de los actos que contemplara dentro de sus aspectos la guerra revolucionaria y todo afiliado o aspirante al partido era un individuo dispuesto en todo momento a cumplir la orden, de cualquier clase y condición que ella fuera, emitida por las directivas de su partido, no importa que se tratara de un acto de sabotaje, un atentado personal, un simple acto de propaganda o una participación activa en la guerrilla. Según las anteriores características que Landazábal Reyes asignaba a la guerra revolucionaria, no hubo ni hay diferencia entre el revolucionario civil y el guerrillero, tesis que desde entonces repercutió en el conflicto armado colombiano. 
Le atribuyó el fundamentalismo a la guerra revolucionaria, de lo cual se desprende que era una guerra sicológica. Desde su perspectiva, el objetivo estratégico de la doctrina militar comunista no es la destrucción de las fuerzas militares del enemigo, sino el dominio de la voluntad de la masa del pueblo cuyas fuerzas armadas se organizan para combatirlo y el objetivo estratégico del comunismo es el dominio espiritual del pueblo considerado como adversario. Este dominio no se logra por los procedimientos de la guerra regular, ni por el éxito de la batalla; se logra mediante el desarrollo de la guerra revolucionaria en todos sus aspectos: la guerra sicológica, el terrorismo, el sabotaje y el atentado personal (Landazábal Reyes, 1966, 11).

Expresó que, mientras el bloque occidental considera la guerra clásica en un primer plano, el bloque oriental, liderado por la URSS, consideró en primer plano la guerra revolucionaria. Estas dos concepciones filosóficas pusieron en pugna los sistemas guerreros. La guerra revolucionaria abarcaba infinidad de aspectos en su realización; llegaba a todos los campos de la vida; se expandía en todas las actividades y afectaba a todas las instituciones. Por ello, según él, se puede decir que era la más total de todas la guerras y, extremando un tanto el concepto, podríamos decir que, dentro del teatro en que se ejecutó, su campo de acción era tan vasto que su realización era casi universal, es decir, que lo abarcaba totalmente e incidía de forma directa en el ambiente social, en el medio, el espacio y el tiempo de la zona que había sido señalada para el ejercicio de sus sistemas revolucionarios (Landazábal Reyes, 1966, 18). Además, señaló que:

La guerra revolucionaria es el resultado de acciones de carácter esencialmente político, donde se utilizan, preferentemente, armas no convencionales, las cuales son, entre otras, la inteligencia, la organización y adoctrinamiento de las masas; el arma sicológica, con la propaganda, los rumores, la creación de expectativas y desconciertos y la acción persuasiva, ya sea individual o colectiva; la influencia política con sus infiltraciones, la lucha de clases y la búsqueda de apoyo en el extranjero; la agitación, los disturbios, los desórdenes, los motines, los incidentes provocados, las manifestaciones de protesta, las asonadas; las actividades clandestinas, la violencia; la cooperación con grupos organizados para fortalecerlos y ganar adeptos y por último la resistencia pasiva para impedir la acción de la justicia (Landazábal Reyes, 1966, 19)

La guerra revolucionaria es, para quienes la realizan, la última razón de su clase, la única posibilidad de vencer los obstáculos que se oponen al progreso, la única opción de realizar los cambios y de poner al día la sociedad con el devenir histórico. Para quienes combaten la guerra revolucionaria, es la expresión brutal de la rebeldía inconsciente, que quiere destruir las estructuras del poder, la concreción de los instintos primarios de los hombres que olvidan la noción de Patria, el camino a la esclavitud (Landazábal Reyes, 1969: 30). Lo primero que surge es la dirección política, sin la cual no podría surgir la guerra revolucionaria; dicha dirección selecciona el área sobre la cual se va a operar, pone en práctica los principios, sistemas y procedimientos de la guerra revolucionaria y fija la política a seguir para el logro de sus propósitos. La dirección política planea, organiza y dirige la subversión (Landazábal Reyes, 1966, 22).

Landazábal consideró que no era la solución en la guerra revolucionaria, como tantos autores lo habían expresado, el mantener, ganar o perder terreno, como sí podría serlo en la guerra clásica; la solución estaba en dominar cerebros, en copar pensamientos. Agregó que era difícil saber cuándo la subversión empezaba a poner en práctica los sistemas de la guerra revolucionaria, por lo cual se llegaba tarde, muchas veces demasiado tarde, "al virus pernicioso que va carcomiendo las conciencias", destruyendo la paz y quebrantando la ley.

Enfatizó que en cuanto a la aplicación de la guerra revolucionaria se refiere, y especialmente cuando ella se desarrollaba en el propio país, era de trascendental importancia para los ejércitos formarse un claro concepto de los motivos que la impulsaban y de las causas que la originaban. Lo anterior, entre otras ventajas en la estrategia antisubversiva, les permitiría precisar la lucha y no desviarse de los objetivos. 
Según él, "no pueden continuar combatiendo la guerra revolucionaria con las mismas leyes que se dictara el pueblo para su desarrollo armónicamente evolutivo" (Landazábal Reyes, 1966, 28)5.

Para él, la guerra revolucionaria había llegado, pues si bien es cierto que los ejércitos no se veían, sus botas no dejaban rastro por ninguna parte, no había uniformes, las formaciones no existían, sí se palpaba el peligro, la incertidumbre, el desconcierto, la zozobra, el incendio, la explosión, la muerte. Era imposible localizar con exactitud a las agrupaciones secretas; el ambiente se tornaba pesado; el vecino se volvía sospechoso, el amigo traidor, el orden se tornaba en caos y la paz en guerra (Landazábal Reyes, 1966, 30).

La guerra revolucionaria tenía un objetivo primordial, esencialmente político: la imposición de ciertas ideas en gentes que las rechazaban. Su objetivo estratégico era la conquista de las masas, para lograr el poder que gravita sobre ellas, el cambio del poder político, razón por la cual no se perseguía con ella la ocupación física de un punto, de una región, de una zona del terreno, de un país determinado; se trataba de la imposición a los habitantes de orientaciones políticas distintas a las que profesaban, para encauzarlos por un sistema de gobierno diferente.

La guerra revolucionaria, según su punto de vista, “....es un virus político que se apodera de todas las mentes, que llega a todos los corazones, e invade todas las arterias vitales de la nación. La guerra revolucionaria es la política armada y fortificada, resuelta a vencer, por todos los medios a su alcance, lícitos o ilícitos; por ello, se efectúa la infiltración política en las instituciones nacionales, en las estructuras del Estado; por ello se hace permanente la acción propagandística y se acude a la abierta contienda de las ideologías, con el respaldo de las acciones, de la guerra irregular" (Landazábal Reyes, 1966, 89).

A diferencia de las acciones de combate de la guerra regular, en la guerra revolucionaria no contaba en forma tan decisiva la superioridad numérica de las organizaciones armadas para garantizar el éxito de la acción, pero sí era indispensable que todos sus

5 Landazábal Reyes, Fernando (Teniente Coronel). 0p, cit., 28. movimientos hubieran sido preparados y calculados en tal forma que se seleccionara para su realización no solamente el sitio adecuado sino el momento oportuno y que estos dos elementos indispensables formaran un "ambiente" integralmente previsto para la acción a realizar. La mejor garantía del éxito en los actos subversivos la constituía el tiempo disponible para su ejecución y en ella, el guerrillero cumplía funciones capitales. Este fue definido en los siguientes términos:

El guerrillero es un soldado de la política, es un político en armas. Sus acciones están guiadas por la perspicacia, la malicia y la intuición de su naturaleza, que habiendo sufrido las asperezas y azares de la vida campesina, halló en el retiro de su aislacionismo la innata desconfianza hacia todo lo que de él se diferencia. Es este el que pudiéramos llamar el guerrillero campesino. No sucede lo mismo con el hombre de la ciudad, que guiado por la misma pasión política, pero animado por un grado de altruismo en sus deliberaciones, llega a la guerrilla campesina para colocarse en ella como puntero que ha de señalar el verdadero rumbo de la ideología a defenderse con la implacable tenacidad de un fanatismo refinado, al calor de una cultura más basta y consciente. Cuando estos dos elementos se confunden en la guerrilla, cuando la temeridad del primero se mezcla con la sagacidad del segundo, la guerrilla alcanza su máxima perfección (Landazábal Reyes, 1966, 131)

Los guerrilleros así caracterizados habrían determinado prioridades, y una de ellas era el ejército regular. Señala Landazábal Reyes que el ejército regular fue un blanco político para el comunismo a través de la guerra revolucionaria; era un objetivo al que debía conquistar por la razón o por la fuerza y las armas más poderosas usadas contra él habían sido siempre el desprestigio institucional y la persuasión individual, especialmente ejercida en la persona del soldado. Con fundamento en los anteriores planteamientos, en lo referente al "enemigo", que actuó mediante la guerra revolucionaria, formuló las siguientes consideraciones.

La base de la guerra revolucionaria es la infiltración política en la estructura del Estado. La guerra 
revolucionaria persigue más una victoria política que una victoria militar. En la guerra subversiva los métodos, las organizaciones y los objetivos son de carácter esencialmente político. En la guerra subversiva el partido de la subversión apoya las tensiones internas. El objetivo estratégico en la guerra revolucionaria es la conquista de las masas. La guerra regular busca la destrucción de las fuerzas armadas del adversario, mientras la guerra revolucionaria busca apoderarse del espíritu de las personas. Por medio de la guerra revolucionaria se pretende dividir a las fuerzas regulares.

En la guerra revolucionaria, una región se gana estratégicamente cuando sus habitantes están preparados para luchar por la idea política del movimiento subversivo. El objetivo de la guerra revolucionaria es derribar el poder establecido para reemplazarlo por su propio sistema. La estrategia política y la militar se confunden en una en la guerra revolucionaria. En la guerra revolucionaria las fronteras con el enemigo son ideológicas e inmateriales. La guerra revolucionaria coordina las técnicas modernas con los métodos primitivos. La guerra revolucionaria pone a la población civil en el centro del conflicto. Uno de los aspectos más álgidos de la guerra revolucionaria es el tratamiento de la población civil. El terrorismo es un arma capital dentro del campo psicológico de la guerra subversiva (Landazábal Reyes, 1966, 255).

Asegura que la guerra revolucionaria en Colombia, igual que en todos los países en los que se ha realizado, ha pasado por etapas debidamente planeadas y ejecutadas con exactitud, solamente obstaculizadas por los actos del gobierno y de las Fuerzas Armadas. Según él, las Fuerzas Militares extrajeron de las nuevas formas de lucha una serie de experiencias invaluables, con base en las cuales se ha ido forjando una doctrina y una táctica peculiar para detener el crecimiento de un estado de subversión. Colombia, afirma, “...ha sido un blanco apetecido por los enemigos de la civilización occidental; en nuestro suelo se han regado, sin visos de fecundidad, todas las semillas de sistemas políticos antagónicos con nuestras aspiraciones y costumbres" (Landazábal Reyes, 1966, 239). En la guerra revolucionaria, los grandes movimientos de los ejércitos de tierra, mary aire fueron reemplazados por los movimientos ideológicos de masas para la conquista de los pueblos; las grandes batallas se trocaron en pequeñas escaramuzas guerrilleras (Landazábal Reyes, 1990, 61). La puesta en práctica de las experiencias, la doctrina y la táctica para detener el crecimiento de la subversión, repercutió en la fisonomía del conflicto armado colombiano.

\section{Sus repercusiones en el conflicto armado colombiano}

Eduardo Pizarro Leongómez le atribuye a Carl Schmitt haber establecido que en las teorías bélicas se deben distinguir el tipo de enemistad que conllevan, dado que esta precisión le otorga a la guerra su sentido y su carácter. La diferenciación de enemigos (relativos o totales) sirve a su vez para distinguir tipos de guerra (acotadas o absolutas). En unas, la guerra encierra una posibilidad de paz y en otras, la solución del conflicto solo puede culminar con la destrucción total del adversario. Si el adversario era percibido como un "enemigo relativo" la guerra podía terminar siendo un instrumento para negociar. Si el enemigo era, por el contrario, absolutizado, la guerra solo podía culminar con la derrota total (Pizarro Leongòmez, 2004, 52). Los grupos marxistas inspirados en autores como Lenin eran portadores de esta última visión, pero también las fuerzas armadas colombianas, en especial Landazábal Reyes influenciado por su vivencia en Corea y por las experiencias antisubversivas francesas en Argelia, bajo el mando de Roger Trinquier.

Estas consideraciones nos llevan a un principio fundamental para comprender la lógica de la guerra: "el enemigo hace al enemigo". La forma como es percibido (enemistad relativa o total), condiciona la forma como el conflicto puede derivar e incluso puede determinar el nivel de crudeza y de barbarie que este asume. En todo caso, determina en gran parte las modalidades de la acción estatal. Por la naturaleza de la noción de guerra revolucionaria de Landazábal Reyes, se infiere que este asumió al socialismo, al comunismo y a las organizaciones guerrilleras de orientación marxista y la guerra re- 
volucionaria en general, como un enemigo absoluto y total $y$, en consecuencia, se le enfrentó de manera total, buscando una derrota íntegra.

En la construcción del enemigo, precisó que:

...el enemigo, no es el soldado extranjero que viola nuestra soberanía, es el propio connacional que se levanta contra sus hermanos, en un gesto supremo de voluntad, de poder; es el hombre del pueblo que se comporta bajo las normas de conducta establecidas; es el amigo del Gobierno que lo aplaude en las plazas y lo combate en la oscuridad; es el empleado oficial que descubre los secretos a ese enemigo, en los arranques de su íntimo coloquio revolucionario; es el maestro que levanta su tribuna de inconformidad sobre las mentes juveniles; es el religioso que desconoce el amor de Cristo; es el obrero que mira con odio a su patrón; es el hombre de la calle; la mujer del hogar; el pobre que sufre la escasez de recursos; es el vagabundo, el ignorante, el científico, el político, el indiferente, el cristiano, el ateo. Allí radica la magnitud del problema subversivo; el enemigo está en todas partes, y sin embargo en ninguna se localiza con exactitud. (Landazábal, 1969, 31)

Desde antes de ser nombrado Ministro de Defensa Nacional, le atribuyó de manera pública y reiterada al Partido Comunista Colombiano y al comunismo internacionalel papel de principal gestor de la lucha subversiva y principal patrocinador de la guerrilla; por ende, era el responsable de las muertes ocasionadas por esta. Identificó en la subversión la existencia de la subversión armada (las guerrillas) y la subversión desarmada (las organizaciones políticas, sociales, sindicales, culturales) que, según él mismo, era la más numerosa y la más peligrosa.

La figura de la subversión desarmada no fue idea original de él; otros militares y políticos de su misma estirpe de derecha, hicieron sus respectivos aportes en la materia. En el año de 1964, el entonces mayor general Gerardo Ayerbe Chaux, en concordancia con la idea la de existencia de la subversión desarmada, adujo que "...vemos con claridad meridiana que en la lucha en que estamos empeñados son más peligrosos los líderes comunistas que se vienen preparando en la "Universidad de la Amistad" de Moscú y en las escuelas de Fidel Castro que los desarrapados e ignorantes bandoleros que aún quedan en algunos lugares montañosos" (Ayerbe Chaux, 1964, 254).

Dos años más tarde, en 1966, ya en condición de Comandante General de las Fuerzas Militares, el general Ayerbe Chaux se preguntó: ¿Será lógico y conducente tratar de controlar la propaganda subversiva, la acción de guerrillas, el terrorismo y ciertas huelgas agresivas haciendo caso omiso de la organización comunista y dejando a fuero de demócratas, campo libre y garantías absolutas a sus dirigentes para actuar contra los principios democráticos? (Ayerbe Chaux, 1966, 3). También en los años sesenta, el entonces coronel José Joaquín Matallana Bermúdez acunó la figura de "bandolero en potencia" para referirse a aquel segmento de la población, independientemente de su adscripción a una clase social, crítico del orden establecido.

El político conservador Álvaro Gómez Hurtado afirmó la existencia del "brazo desarmado de la subversión". Durante la administración del presidente Julio César Turbay Ayala, el Ministro de Justicia, Hugo Escobar Sierra (conservador) adujo la existencia de "la subversión desarmada", la cual definió en los siguientes términos: "Es la que muchos ejercen criticando a las autoridades, censurándolas, destruyendo la imagen de la autoridad legítima, y de esta manera, contribuyendo a la inseguridad y estimulando a los grupos subversivos" $(1979,2)$. Según Turbay Ayala, había "gentes de bien" y los "enemigos de la nación" (Vásquez Carrizosa, 1979, 39).

Estas maneras de entender el fenómeno de la subversión en Colombia por parte de las elites militares, políticas y económicas, pasó a ser de uso habitual en distintos estamentos de la sociedad, entre ellos, la Corporación Acción Colombia, según la cual la subversión desarmada, "infiltrada en el estamento legal, ha hecho quizás más daño a la nación, que las bandas de forajidos que deambulan por campos y ciudades sembrando el desconcierto, la desinformación y el terror" (Corporación Acción Colombia, 2002, 33). Según esos supuestos, la penetración de la subversión en Colombia habría pasado por siete pasos. 
1. Una sociedad libre pero erosionada.

2. Una sociedad amenazada.

3. Una sociedad desestabilizada.

4. Una sociedad en crisis.

5. Una sociedad en caos.

6. Una sociedad dominada por un gobierno marxista narcoterrorista.

7. Una sociedad esclavizada por las guerrillas comunistas.

Desde la perspectiva de Landazábal Reyes y en concordancia con la anterior visión, se consideró que "el verdadero enemigo" era la Unión Patriótica, con su "brazo armado", las FARC, y su brazo sindical, la Central Unitaria de Trabajadores. Situadas en esta apreciación de los acontecimientos, las derechas colombianas consideraron que, a raíz de los diálogos de paz liderados por el presidente Belisario Betancur Cuartas (1982-1986) y la amnistía otorgada por este a las organizaciones guerrilleras, supuestamente se le habían hecho excesivas concesiones al conjunto de la subversión colombiana, la cual, desde su lógica y a partir de la guerra revolucionaria, habría emprendido una sistemática penetración de todas las instituciones hasta carcomer los cimientos mismos del orden establecido.

Ante este sombrío panorama, la política de la eliminación de la subversión desarmada tomó forma, ante el supuesto derrumbe de las instituciones. Dicha tarea, emprendida por miembros de los organismos de seguridad del Estado, aliados con organizaciones paramilitares (Piccoli, 2005, 118), y estos apoyados por gremios de la producción y el narcotráfico, desataron una escalada de asesinatos individuales y colectivos tendientes a extirpar a la subversión desarmada del panorama político colombiano, con particular ahínco desde 1997, cuando se aglutinaron en las Autodefensas Unidas de Colombia (consideradas por Landazábal Reyes "la subversión contra la subversión"). Desde los años ochenta del siglo XX, tuvo lugar una las más complejas y críticas coyunturas de la historia del conflicto armado colombiano, caracterizada, entre otros aspectos, por la degradación, consistente en la sistemática violación del Derecho Internacional Humanitario, el asesinato de civiles no necesariamente simpatizantes de las organizaciones guerrilleras, los desplazamientos forzados (Atehortúa et al., 2009, 34), la expropiación de tierras y la impunidad.

A la guerra revolucionaria se le habría hecho frente con una guerra informal, en parte usando su propia estrategia. Desde la noción de guerra revolucionaria de Landazábal Reyes, construida a partir de su subjetividad individual y social, en el marco de la Guerra Fría, al encontrar eco en estamentos dominantes y en grupos de presión legales e ilegales, fue configurada una estrategia antisubversiva cuyos elementos centrales configuran las formas y los contenidos de las maneras en que las derechas y el estamento castrense asumen el conflicto armado colombiano. 


\section{Referencias}

Acción Católica Española .(1955). Colección de encíclicas $y$ documentos pontificios. 4 Edición. Madrid: Publicaciones del Junta Técnica Nacional.

Atehortúa C, A., Rojas, Diana Marcela y Guillou, Ronan. (2009). Reflexión para la planeación. Seguridad democrática y política antidrogas. Bogotá: Aurora.

Ayerbe Chaux, G. (General). (1966). Un problema nacional. Revista de las Fuerzas Armadas. Número 40, Volumen 14. Bogotá, septiembre/octubre de 1966.

Ayerbe Chaux, G. (Mayor General) .(1964). La rebelión en Colombia. Revista de las Fuerzas Armadas. Número 29, Volumen 10. Bogotá, noviembre/diciembre de 1964.

Corporación Acción Colombia .(2002). La cara oculta del enemigo. Estrategia subversiva para la toma del poder en Colombia. Bogotá: Preprensa Digital Gráficos.

Donoso, J. (2006). Ensayo sobre el catolicismo, el liberalismo y el socialismo. Granada, Comares.

Durán, D. (2008). El hombre del número 13. El Espectador. Bogotá: mayo 11 de 2008.

(1982). Ejército: la hora de Landazábal. Revista Semana. Número 12. Bogotá, 27 de julio-3 de agosto de 1982.

Fuerzas Militares. (1998). Escritos inéditos del Señor General Fernando Landazábal Reyes. Bogotá.

Garthoff, R. L. (1956). Doctrina militar soviética. Madrid: Aguilar.

González Rey, F. L. (2002). Sujeto y subjetividad. Una aproximación histórico-cultural. México: Thomson.

(1996). Grupo de notables, con el Fiscal. El Tiempo. Bogotá, 8 de abril de 1996.

(1979). La "Subversión desarmada". Revista Alternativa. Número 230. Bogotá, 13-20 de septiembre de 1979.

(1962). La guerra interna nueva táctica comunista. Revista del Ejército. Número 9. Bogotá, Agosto de $1962,687$.

(1982). Landazábal nuevo estilo. Revista Semana. Número 17, Bogotá, 31 de agosto-6 de septiembre de 1982.

Landazábal Reyes, F. (Teniente Coronel). (1966). Política y táctica de la guerra revolucionaria. Bogotá: Editorial Pax.

Landazábal Reyes, F. (Coronel). (1969). Estrategia de la subversión y su desarrollo en la América Latina. Bogotá: Editorial Pax.

Landazábal Reyes, F. (Brigadier General). (1975). Factores de Violencia. Bogotá: Ediciones Tercer Mundo.
Landazábal Reyes, F. (General). (1990). La salida del túnel. Bogotá: Planeta.

Medina, M. (2000). Las tropas siguen al líder si se compromete con ellas. Entrevista con el general ( R ) Fernando Landazábal Reyes. Revista Análisis Político, Número 39, Bogotá.

Piccoli, G. (2005). El sistema del pájaro. Colombia, paramilitarismo y conflicto social. Bogotá: ILSA.

Pizarro Leongómez, E. (2004). Elementos para una sociología de la guerrilla colombiana. Guerra en Colombia: actores armados. Bogotá: FICA.

Vásquez Carrizosa, A. (1979). Perversión del Estado de sitio (V). La institucionalización. Revista Alternativa. Número 214. Bogotá, 23-30 de junio de 1979.

Yarce Maya, J. (1981). Un general que habla claro. Revista Arco. Número 250, Bogotá, noviembre de 1981. 